\title{
Dossiê
}

\section{Los lugares de la oscuridad: epistemología náhuatl de los procesos vitales y modelos técnicos}

\author{
Marie-Noëlle Chamoux \\ CERMA/École d'Hautes Études en Sciences Sociales
}

RESUMO: Entre os Nahua antigos e contemporâneos há uma forte preocupação epistemológica sobre a possibilidade de conhecer $\mathrm{o}$ funcionamento do universo, ressaltando a invisibilidade e a ininteligibilidade dos processos de vida e morte. Eles dizem que esses processos ocorrem em "lugares noturnos", na escuridão. Esses lugares estão no interior das sementes e dos corpos dos seres animados, incluindo a Terra, vista como um animal gigante. Objetos de uso cotidiano - casa, xícara, garrafa, panela, caixa, pano, tear, chapa de barro - servem de metáforas para esses lugares e para o que eles revelam aos homens. Os Nahua usam o modelo do trajeto do sol para localizar lugares de escuridáo e comparam a vida com a textura das plantas em crescimento. Este artigo descreve as rotas, as divindades terrestres e suas funçôes, bem como as tecnologias utilizadas como metáforas de açôes divinas para a criação da vida. Examina, particularmente, algumas analogias com métodos culinários de preparação do milho.

PALAVRAS-CHAVE: Nahuatl, morte, vida, mundo subterrâneo, Terra, divindades, objetos cotidianos, cozinha. 
Los pueblos mesoamericanos antiguos han construido su cosmovisión a partir de una premisa fundamental: la imposibilidad de conocer completa y claramente cómo funciona el universo, en particular la vida y la muerte ${ }^{1}$. Sus herederos contemporáneos también se interrogan: "Vemos que funciona el mundo... pero no sabemos cómo". El hombre ve sólo parcialmente eventos, sin poder conocer lo que los mueve, sus fines, lo que ocurre en ellos. Topa con una opacidad que impide su vista.

Una repuesta a la ininteligibilidad consiste en formar conjeturas y compararlas con procesos o eventos conocidos por la experiencia humana: se recurre a analogías, a representaciones icónicas, a metáforas y sus variantes. Para imaginar la vida y sus cambios, la gente escoge modelos en fenómenos naturales o bien en artefactos de origen humano, como objetos y técnicas. ¿Cómo se entretejen entonces las imágenes que se originan en ordenes diferentes? Es una tarea clásica de la antropología la de descifrar representaciones, a partir de señales que la propia gente del grupo reconoce como pertinentes, con el fin de establecer un modelo interpretativo de tipo emic, apoyado en argumentos empíricos fuertes. Por analogía con la lingüística elemental, se tiene que identificar y comprender los elementos culturalmente seleccionados; las denotaciones y connotaciones del léxico por sus usos; el sentido de las frases para los locutores; las situaciones discursivas, reconstituyendo su implícito y el no verbal. En breve buscamos acercarnos, de la mejor manera posible, al manejo de los contextos lingüísticos y circunstanciales y a los patrones que guían la interpretación y la acción de los nativos. Este paso descriptivo, por muy conocido que sea, es de recordar siempre pues constituye el corazón de la disciplina antropológica.

También resulta útil la famosa trilogía de Peirce que distingue el indicio, marca que tiene relación real con lo representado o referente; el icono, marca que tiene analogía con lo representado; y el símbolo, marca convencional que no tiene relación con lo real. En nuestra interrogación, consideramos principalmente los fenómenos que tocan a los indicios pertinentes y a los iconos compartidos en una determinada comunidad humana.

Del mismo modo resulta imprescindible tomar en cuenta la deixis, o perspectiva que implícitamente adoptan los interlocutores. En nuestro estudio, es particularmente importante la deixis visual que hace variar las distancias, los ángulos de vista (frontal, lateral, superior, en corte o en sección, desde el interior de la escena, en volumen, etc.).

Fundamentalmente, un determinado grupo puede analizarse como una comunidad de prácticas, cuyos miembros comparten un mismo repertorio informativo, verbal o no 
verbal, y entienden inmediatamente los implícitos y explícitos en la comunicación y en la interacción (Wenger, 1998)². La vida cotidiana constituye una fuente importantísima para construir el repertorio común. Con ciertas condiciones, tal repertorio, aun implícito, no está completamente fuera del alcance de un observador externo: las encuestas de campo en inmersión permiten al investigador un cierto acceso a la vida cotidiana y en consecuencia a partes importantes del repertorio común. El analista experimenta porciones del mundo de vida que rodea a la gente y da sentido a sus acciones (Habermas, 1987). Las referencias comprenden entonces muchos objetos domésticos y de procedimientos técnicos corrientes, usados metafóricamente.

Desde Braudel, se reconoce que categorías de pensamiento y modelos de acción se relacionan con la "historia lenta" colectiva o "larga duración", modelos que en ciertas condiciones pueden sobrevivir más allá de los accidentes históricos (1959). Una estabilidad se encuentra en las técnicas cuando éstas se siguen usando. No hay dudas que objetos, procedimientos y gestos técnicos antiguos persisten hoy en Mesoamérica. En éstos encontramos una base material compartida tanto por poblaciones prehispánicas como actuales. Autoriza entonces a cotejar con precauciones las informaciones de siglos diferentes. Aunque nuestro enfoque examine el caso de los Nahua, a veces indicamos el eco que se encuentra en otros pueblos antiguos o actuales de México y Guatemala, pues se admite la existencia de una área cultural mesoamericana con rasgos comunes (Kirchoff, 1943).

Se necesita una advertencia: no se pretende describir en totalidad las concepciones de los Nahua respecto a la vida y a su formación. Se trata aquí de semiótica, que pone en relación signos y referentes. El enfoque da la prioridad a algunas metáforas discursivas o iconográficas que se inspiran de objetos, procesos y gestos cotidianos. Aún así, no se pretende a la exhaustividad, la cual llenaría un volumen.

El material empírico que usamos proviene de varias fuentes. La documentación sobre la lengua náhuatl clásica del siglo XVI sigue funcionando bien para los dialectos contemporáneos $^{3}$. A pesar de cinco siglos de contacto, la permanencia de prácticas y concepciones indígenas ya no se discute, y la única cuestión es: ¿Hasta cuándo sobrevivirán? La situación presente autoriza interrogar tanto grandes fuentes históricas de la época colonial que conciernen el valle de México (Anahuac) como datos etnográficos recientes, que escogimos entre los que proceden del oriente de México (Norte de Puebla, Sierra de Puebla y Huasteca). Antes de la Conquista, atravesaban esta área rutas importantes entre el 
Anahuac y la costa del Golfo de México. Hoy el idioma náhuatl presenta tres variantes en la zona: el dialecto de tipo central del norte de Puebla, el náhuat (sin - tl) de la Sierra de Puebla y el dialecto de la Huasteca, ligeramente diferente del central. Disponemos de observaciones directas de la vida cotidiana de los Nahua del norte de Puebla (municipio de Huauchinango y de Naupan) desde 1969 hasta 2010, y alcanzamos cierta competencia práctica en su dialecto de tipo central. Los otros datos proceden de relaciones antiguas o recientes y del examen de objetos materiales.

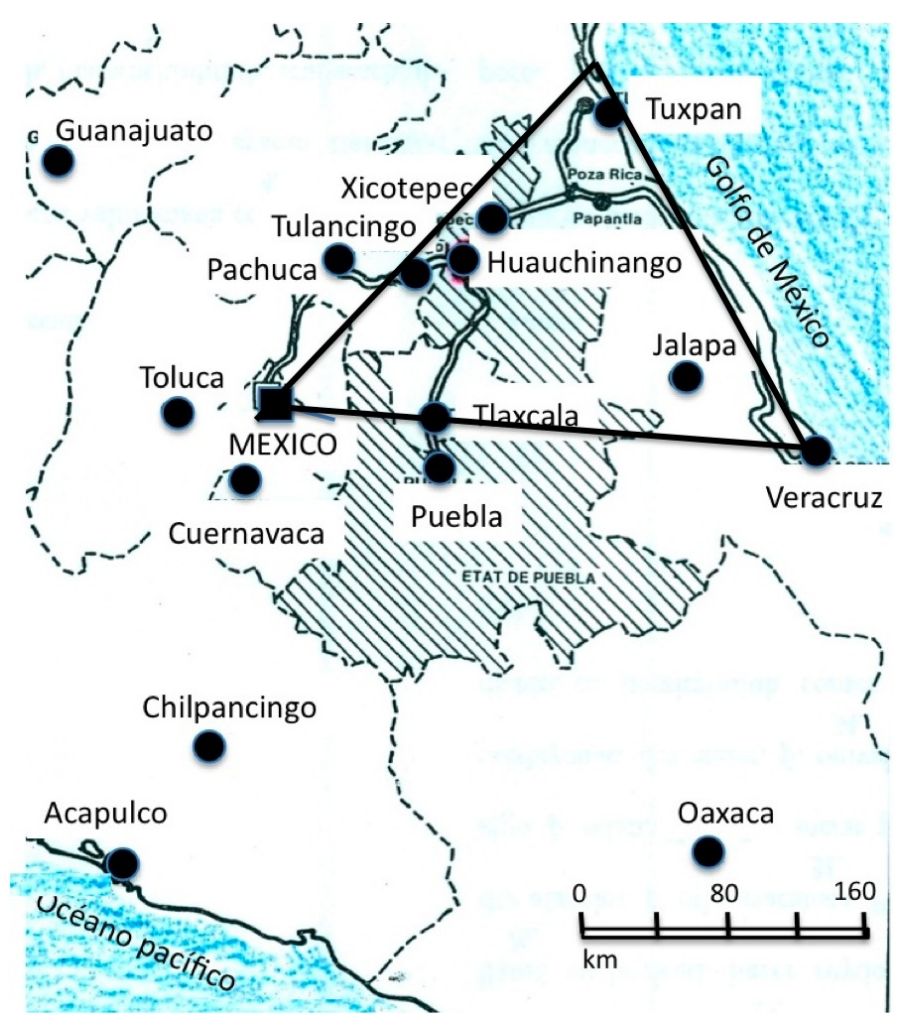

Figura 1: Área oriental con grupos nahuas, del Anahuac a la Huasteca

\section{Categorizar la vida en náhuatl}

El criterio epistémico náhuatl separa lo que el hombre puede observar de visu desde la superficie terrestre y lo que no puede ver porque está hundido en la oscuridad, o bien porque se halla detrás del sol que deslumbra. 


\section{Categorizar la vida visible}

Una categoría general del "vivir" se ve muy claramente en el léxico náhuatl y se aplica a una gran variedad de entidades y seres existentes del mundo. Se expresa con el verbo nemi, moverse, andar, que equivale a existir (en el espacio-tiempo), con el nombre derivado nemilistli (Chamoux, 2012a). Se usa también para evocar un modo de vida y para funcionar (to run). El significado del verbo se asemeja al verbo latino cedo, cedere, que ha dado “proceso". Dicha existencia constituye un modelo que se aplica a todos los seres de la biota - los vegetales más los animales - y también al sol y a otros objetos celestes considerados como animados. Implica un desplazamiento temporal que se acompaña de cambios intrinsecos en el sujeto que se mueve, sea éste un existente de la biota o el sol u otro astro.

Categorizaciones más específicas se aplican a integrantes de la biota. Una categoría del léxico diferencia claramente la vida como esencia (yolistli, del verbo yoli, nacer, ser vivo, del cual deriva yollotl, corazón) y el proceso de existencia temporal evocado (nemilistli, de nemi, andar). Aunque todos "andan", sólo animales (genérico: yolcatl) y hombres (genérico: tlacatl) viven por esencia (yoli): son los yolque', los que poseen la vida, los vivos strico sensu (Beaucage, 2009; Chamoux, 2012a). Los procesos de cambio vital en la biota se nombran de modo distinto: las plantas "crecen" (ixua), mientras hombres y animales "viven" (yoli) (Wimmer, s.f.; Beaucage, 2009: 144).

Otra categoría organiza los existentes de la biota según el criterio epistémico del modo visible de su comienzo. Beaucage precisa que se distinguen:

- los que tienen un origen visible, con órganos sexuales o bien semillas, huevos, larvas que los hombres conocen;

- los que "no más se hacen" (mochinaj saj, escribe Beaucage; en dialecto central: mochiua' san) por generación espontánea, por ejemplo hongos, ciertos gusanos, etc. que, según dicen, surgen del agua, de la madera, se caen de las estrellas, etc.

\section{Categorizar lo invisible}

Lo que no se conoce da lugar a conjeturas, que los académicos suelen nombrar religión o cosmovisión. El concepto global es él de oscuridad para designar sea la ininteligibilidad, sea 
el conjunto de sitios y momentos que intervienen en la producción y el manejo de la vida. La experiencia humana enseńa que la oscuridad esconde. Su propiedad es de no permitir el buen ejercicio de la vista, idea muy corriente en el mundo pero reiterada con fuerza en Mesoamérica y integrada en mitos. Lo ininteligible o lo oculto se expresa en náhuatl por una metáfora lexicalizada o no: la noche, física o metafórica. El término noche se lexicaliza para formular el concepto general de oscuridad, de tinieblas: yohualli o youalli, la noche, y sus derivados, tlayoualli, lo oscuro de algo, y las formas abstractas youallotl y tlayouallotl. Provienen de un radical verbal que designa un proceso: youa, anochecer. Su opuesto es otro radical verbal de proceso: nesi (algunos escriben nezi o neci), aparecer. El derivado tlanesi, amanece, se opone a tlayoua, anochece. La oscuridad se contrapone, no tanto con el estado de luz, sino con el movimiento de aparecer (nesi), de manifestarse, de volverse visible tanto en el mundo físico como en el intelecto. Es el amanecer. Es también el acceso al saber (el maestro "hace aparecer algo" al alumno).

El concepto de oscuridad engloba subcategorías, como lo confuso y lo oculto. En representaciones verbales e iconográficas, es frecuente la alusión a un estado confuso o nebuloso, expresado por metáforas que se refieren a las nubes (mixtli) y a la neblina $(\text { ayauitl })^{4}$. Se aplica a comportamientos solapados: la mala anciana es "xomolli, tlayohualli, caltextli, mixtecomatl', el rincón, la noche, la pared, el tazón de nubes (Sahagún, 19501982, v. 10: 11). Lo oculto caracteriza el secreto, o itztacayotl cuando se refiere a acciones humanas muchas veces reprensibles - "regularmente lo toman in malo paro, y así llaman el hijo ilegitimo, o adulterino itztacaconetl, y al ladrón ixtequi, porque siempre hacen a escondidas sus huertos” (Anónimo, s.f.: bnf 362). Lo oculto también caracteriza el "nahualismo" o nauallotl, transformación nocturna de un hombre en animal concordando con un elemento íntimo y peligroso que reside en cada persona humana. En fin, lo oculto es el misterio inherente a lo divino, con indicios visibles e inteligibles sólo para los dioses, teotlanezcauotilistli o teonezcayotilistli (Anónimo, s.f.: bnf 362).

Lo oscuro, lo confuso, lo oculto justifican la existencia de una función social, la de sacerdote indígena o adivino, que actúa como médium capaz de ver cosas ocultas o nebulosas, de origen divino o humano ${ }^{5}$. El estatus de hombres videntes y poderosos capaces de penetrar la oscuridad o la nebulosidad, se encuentra en toda el área mesoamericana antigua y contemporánea ${ }^{6}$. 
Para los Nahua, no hay duda que la vida es doblemente oscura: es un misterio divino y se termina y empieza en sitios oscuros. Decía la partera azteca hablando del niño por nacer: "Ipampa ca oc Mictlan ca oc youayan in tontla'toa", "Ahí está todavía en Mictlan, está todavía en la noche, éste [niño] del cual hablamos" (Sahagún, 1950-1982, v. 6: 154). La cita designa uno de los lugares que intervienen en las ideas nahuas sobre la vida: Mictlantli (locativo: Mictlan), lugar de los muertos, descrito como sin aperturas ni ventanas (Launey, 1980: 287). A la partera y pediatra, la nombraban youalticitl, médica de la oscuridad.

Visto por un observador nahua, la oscuridad es una propiedad del interior de algo. Muchos objetos del mundo tienen un interior oscuro, o una parte menos visible abajo o debajo de ellos. Tienen un interior los miembros de la biota (humanos, animales, semillas), la Tierra, una cantidad de objetos hechos de mano humana. Éstos últimos se usan frecuentemente como metáforas de los sitios donde se produce la vida. Conocerlos nos permite compartir analogías con los nahuas y así preparar nuestra mente para una mejor comprensión de las teorías mesoamericanas de la vida.

\section{Artefactos con oscuridad o penumbra interior}

Por tener un exterior y un interior oscuro, varios contenedores cotidianos sirven de referencia en la lengua y la iconografía antiguas y contemporáneas.

Contenedores abiertos: casa, cantimplora, tazón, olla...

El término calli, casa, designa todo lugar u objeto clausurado en general (Launey, 1980: 295). Las propiedades de la forma "casa" son de las de tener límites materiales, opacos, delimitando un espacio de tres dimensiones, con un interior y un exterior. Su radical -calse convierte en clasificador para muchas cosas: temascalli, baño de vapor; acalli, canoa; caltechtli, pared; petlacalli, cofre de cesto; xicalli, tzoa'calli, jícaras, etc.

Otros recipientes, con propiedades espaciales comparables, aparecen con otros clasificadores. Encontramos contenedores vegetales, de la familia de tecomatl (cantimplora, tazón), para beber líquido (agua) y algo semilíquido viscoso y opaco (atole, chocolate, 
pulque, etc.). También figuran recipientes de cerámica, de la clase de comitl, olla de barro usada para hervir alimentos y para almacenar agua o víveres, entre éstos el temetzcomitl, olla "luna" para cocer con vapor. Notamos que comparan a ollas las reservas divinas de agua, que suponen guardadas en los cerros (Sahagún, 1950-1982, v. 11: 247; Knab, 1991: 42), y en la luna (Cuacuila, datos de campo 1969 a 2010) ${ }^{7}$, en la cabeza, en la vagina (Beaucage, 2009: 314), etc.

\section{CALL]}

Casa

Cabi

Baño de vapor
Temascallis

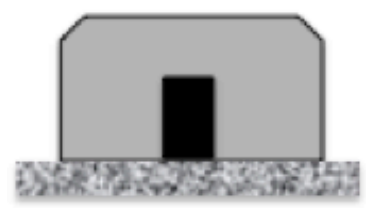

Tazones

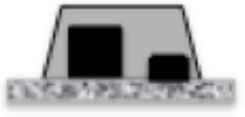

TECOMATL

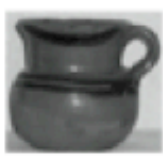

Canoa

Acalli

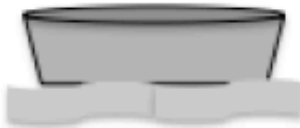

Cantimplora

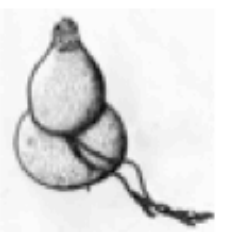

Jicara

Xicalli

Traa'calli

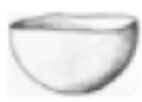

Panera
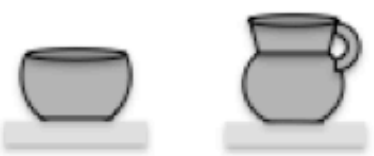

Figura 2: Perfiles de artefactos con oscuridad o penumbra interior

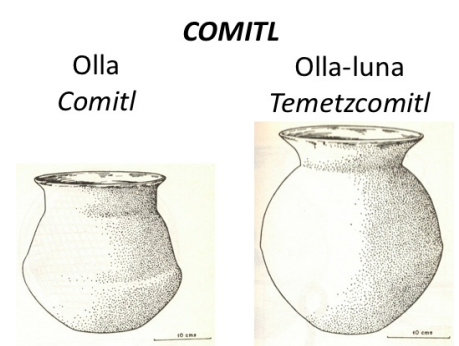

Contenedores con tapadera: baúl, caja

La oscuridad intensa se expresa con metáforas de contenedores tapados o cubiertos. Los arquetipos de estos objetos son el baúl y la caja: in toptli, in petlacalli. 


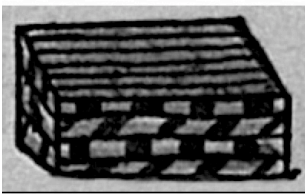

Toptli

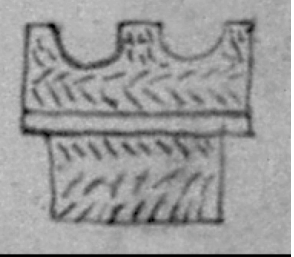

Petlacalli

Figura 3: Contenedores con tapadera

Amoxcalli, diccionario de glifos en línea

Estás metáforas se aplican al origen de la vida. Los ancianos, asombrados ante el prodigio de la concepción y de la gravidez, decían a los parientes de la muchacha preńada: "ca nican tictlapoa in toptli, in petlacalli: a ca nican tontlamauisoa, a tontlachia in atotlachiaia, in atotlacaca'quia": ahora aquí abrimos el baúl, la caja: ahora aquí nos admiramos con respecto, miramos lo que no deberíamos ver ni entender (Sahagún, 1950-1982, v. 6: 137), y el tema se repite: "ca otitlachixque' in topco, in petlacalco, in a'totlacanquiyan, in a'totlachiyayan, in a'totlamatiyan" (Launey, 1980: 96-97), hemos mirado en el baúl, en la caja, en el lugar adonde no correspondía a nosotros [los hombres] entender, mirar, conocer.

Con las mismas metáforas se habla de la intimidad subjetiva de un existente - "ca onontlachix in topco in petlacalco", pues lo que observé queda en mi baúl, en mi caja (Sahagún, 1950-1982, v. 12: 6), o bien de los poderes divinos - "in itop, in ipetlacal in tlacatl, toteucyo, in tetzahuitl, in huitzilopochtli", "el baúl, la caja del dueño, nuestro señor, él que es agüero, Huitzilopochtli”(Sahagún, 1950-1982, v. 9: 55). En Chicontepec, hoy, cielo y tierra se representan acostados en baúles (Báez Jorge y Gómez Martínez, 2000: 86). Muchos mitos contemporáneos relatan que los fenómenos meteorológicos y los atavíos de los dioses de la tormenta se guardan encerrados en baúles ¡Maldición de aquel que se atreve a abrirlo! Lo narra una señora de Cuacuila en un cuento de un hombre que los dioses del trueno se llevaron:

(...) el hombre dice: "Bueno, dice, yo puedo vestirme para ir también. ¿Cómo que sólo los dioses puedan ir para levantar la lluvia, y que yo no pueda? Les voy a seguir (...)”. Abrió una caja (hispanismo: caxa'tli). Viene 
saliendo puro viento, hasta una tornada. Bueno, ahí la cerró. Se fue a abrir otra caja. Viene saliendo puro granizo. Bueno entonces ahí la cerró. Entonces es en otra caja que encontró la ropa de vestir y la desplegó. (...) Ahí se quedó como haciendo rayos y rayos (datos de campo, Cuacuila 1970).

Y esto produjo una espantosa tormenta que empezó a destruir al mundo. En el mismo pueblo, Iván Pérez Téllez encontró la mención de una "caja de bronce" que abren los entes de la lluvia (2002: 66). En la sierra de Puebla, Knab menciona que la misma función de reserva de tormentas la cumplen ollas guardadas en el inframundo (1991: 42).

\section{Artefactos evocando una parte inferior}

Otra manera de evocar un lugar oscuro lo sitúa “abajo”, Tlatzintlan, es decir en la parte baja de algo. Se usa para la Tierra y algunos existentes del mundo, en particular el cuerpo humano. En la escritura antigua, la silaba $t z i n$ (o $t \sin$ ) se notaba de modo figurativo con la mitad inferior de un hombre, porque el lexema tzintli significa nalgas, ano, culo. Los glifos la representan sea verticalmente, sea horizontalmente con perspectiva lateral.

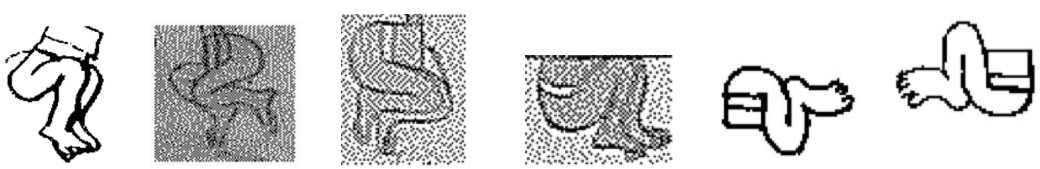

Figura 4: Algunos signos para la silaba trin

(Cortesía de Marc Thouvenot) ${ }^{8}$

Para comprender las analogías con artefactos, debemos adoptar una visión superior más o menos distante, con un ángulo de vista correspondiente al sitio real del ser humano vivo en la cara superior de la Tierra, dicha Tlalticpactli (locativo: Tlalticpac). 


\section{Mantel o tela, y telar de cintura}

Algunos artefactos connotan la oscuridad porque delimitan una parte inferior. En un libro de texto en náhuatl de la secretaría de educación pública para la zona del norte de Puebla, encontramos un dibujo y un comentario intitulado "El mundo de los antiguos mexicanos" (Romualdo Hernández, 2000: 36). Este libro fue redactado por maestros de habla náhuatl originarios de los pueblos del área:

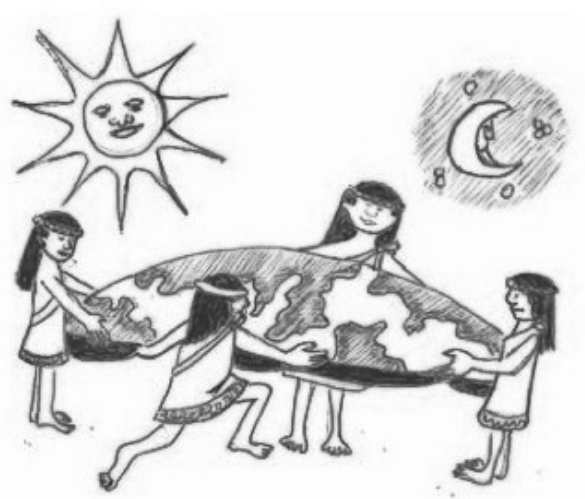

Figura 5: El mundo de los antiguos mexicanos (SEP)

(C) Marie-Noëlle Chamoux, según Sánchez, in Romualdo Hernández, 2000: 56

El Tlalticpactli, él, es para siempre un mantel, él para siempre estará mandando, nosotros no es lo que tenemos, solamente estamos de paso en su cara dos o tres años, en su cara nos pasamos [la vida] trabajando, una vez él nos hizo germinar, [después] vamos, [en fin] llegamos en la boca del Tlalticpactli. ' (Romualdo Hernández, 2000: 56)

El lexema que traducimos por mantel es él que significa urdimbre (tletectli). El dibujo coloca la tela a la altura de la cintura de cuatro deidades que la extienden. Esta posición recuerda la de la urdimbre cuando una mujer teje con telar de cintura. La parte superior del cuerpo queda arriba del plano de la urdimbre, y la parte inferior, tzintli, queda debajo, en una relativa penumbra. Se nota en la figura 5 que la orilla del mantel se marca por una cinta de color oscuro, detalle se refiere a la forma del mundo. 


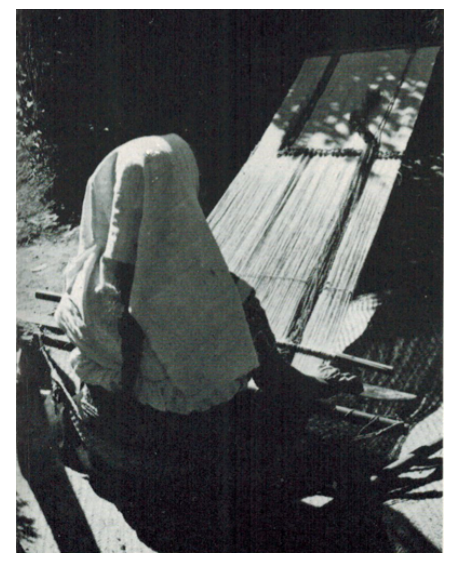

Figura 6: Telares de cintura
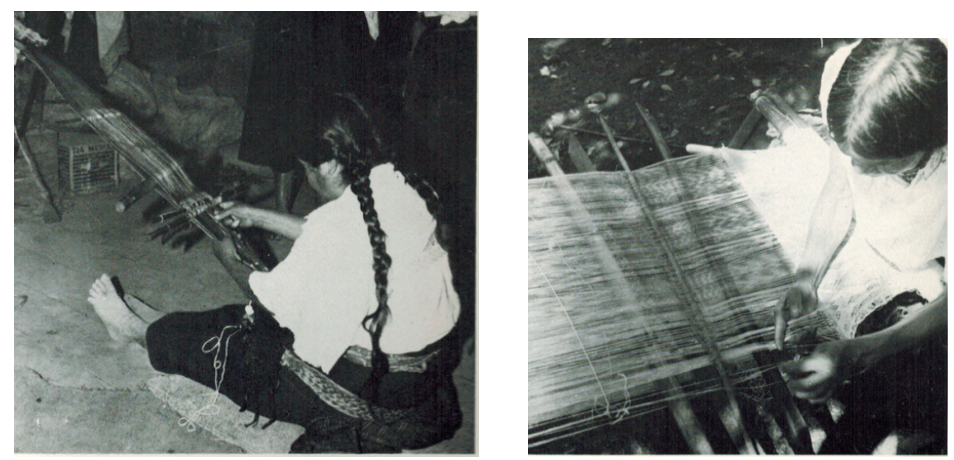

(C) Victor Lagarde CEMCA

(C) Marie-Noëlle Chamoux CEMCA

La analogía del tejer con el signo icónico de escritura tzin, que separa visualmente la parte baja del cuerpo, queda una buena probabilidad. Otra correspondencia con el tejido se encuentra en la etimología. El locativo -cpac entra en la morfología del nombre de Tlalticpactli. Launey sugiere que este locativo viene de icpatl, hilo, y da como traducción literal "sobre el hilo de la tierra" (Launey, 1988: 181). El límite entre "encima” y "debajo" podría ser representado por hilos tendidos.

Un va y viene se instaura comúnmente entre imágenes del cuerpo y las de artefactos: en el comentario de la figura 5, en la misma frase se entretejan la metáfora del mantel y la de la boca de la Tierra.

Comal

Un artefacto circular sirve para representar la posición del hombre en el mundo. El simbolismo cosmológico del comal, por su forma y funciones, es muy claro y está atestiguado. En Cuacuila, dicen que el mundo es "como un comal" (comalli), disco de barro que sirve en la cocina para cocer tortillas o pan de maíz y para tostar alimentos. Es también lo que dicen los Nahua de toda la zona (Chicontepec: Báez Jorge y Gómez Martínez, 2001: 403; Sierra de Puebla: Lupo, 2001). Un comal se presenta como un artefacto discoidal con reborde. La perspectiva superior (bird view) es de hecho la más frecuente cuando se usa el comal. 

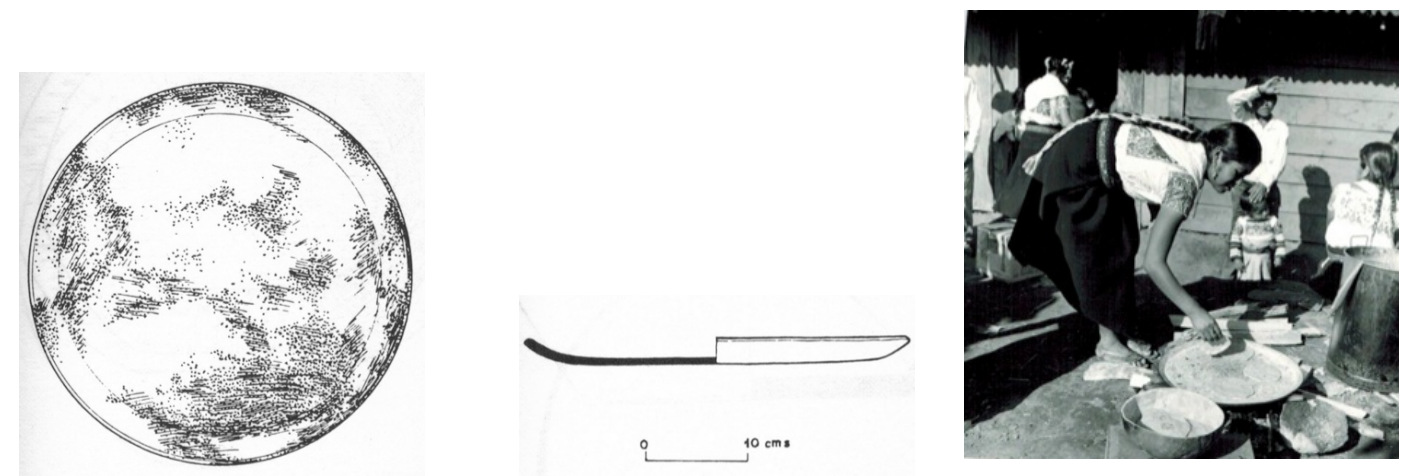

Figura 7: Comal y posición de uso en el área de Huauchinango, Puebla

(C) Françoise Bagot, CEMCA

(C) Marie-Noëlle Chamoux, CEMCA

Otras informaciones permiten proseguir en detalle la metáfora. "El mundo está como rodeado de cerros", precisa un informante de Cuacuila. En Chicontepec, hablan de faldas, tlacueitl, "que se imaginan como 'muros de contención'(...) para evitar la salida de las aguas marinas” (Báez Jorge y Gómez Martínez, 2000: 82). La forma en corte del comal dibujado - la misma se encuentra en toda la Mesoamérica - muestra efectivamente un reborde. Probablemente el pintor de la figura 5 tenía esto presente cuando puso una cinta oscura alrededor del mantel terrestre. En estas metáforas, el locutor se posiciona encima del plano, pero en contacto íntimo con él (en náhuatl existe un sufijo locativo específico: -tech).

Figura 8: El hombre encima y adentro del comal terrestre

Otras características del artefacto comalli son significativas. Un comal - tradicionalmente de barro - tiene cierto espesor, lo que lo asemeja a la corteza terrestre. Debajo de él se pone la lumbre para tostar los alimentos. La figura 9 muestra como los pueblos antiguos representaban el Viejo Dios del Fuego soportando un disco. Se conocen centenas de imágenes antiguas de él (ver ejemplos en Teotihuacan, Cité des Dieux, 2009). El objeto reproduce la posición del fuego y del comal que se observa diariamente, hasta la fecha, 
en cada cocina tradicional mesoamericana. Esta deidad tiene un papel importante en las representaciones de procesos vitales.
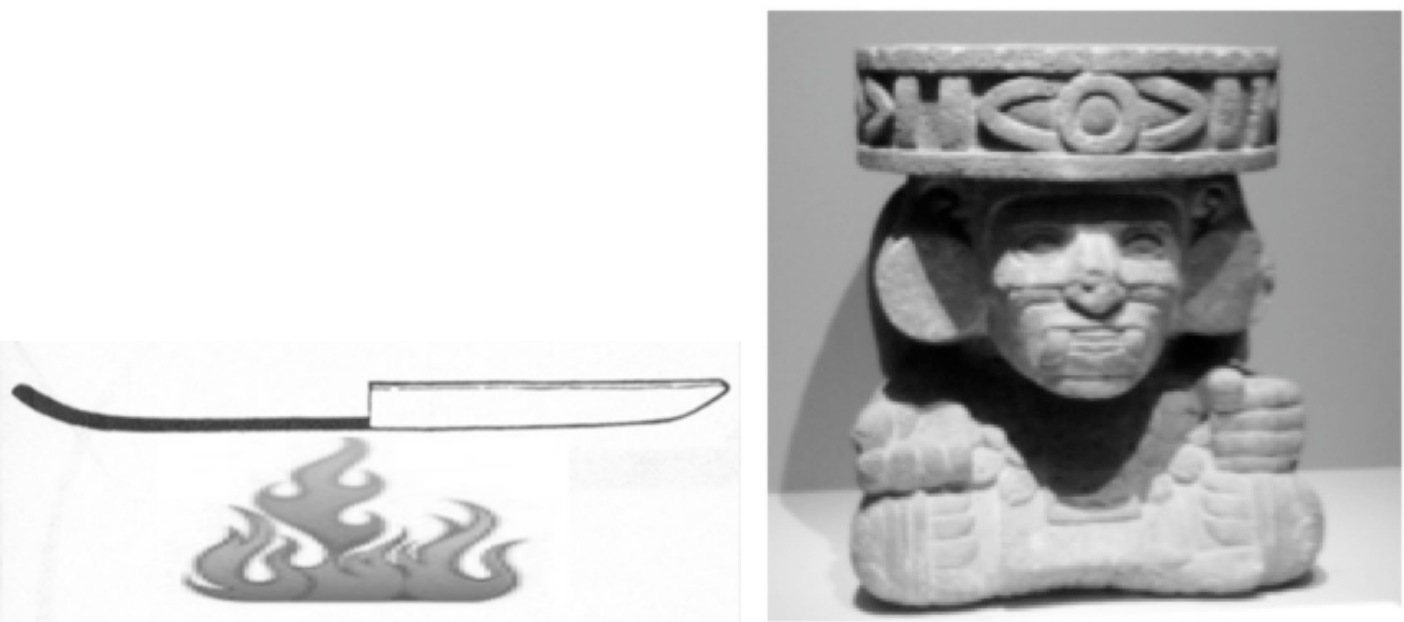

Figura 9: Comal y Viejo dios del fuego (Teotihuacan)

CFoto Marie-Noëlle Chamoux

La oscuridad y la penumbra son fenómenos a la vez físicos y cognitivos, y la epistemología nahua afirma la imposibilidad para los seres humanos de conocer completamente lo que pasa en los interiores. El hombre tiene acceso solamente a señales o indicios, parciales por definición, sobre el funcionamiento de la vida. Los objetos presentan formas para iconos, a manera de patrones o prototipos. Las diferentes imágenes subrayan, según los contextos, el enfoque sobre unas u otras propiedades de los "lugares de oscuridad" donde se maneja la vida.

- Las comparaciones con casa, tecomates, ollas y aparentados, dirigen la atención hacía el interior, especialmente el de la Tierra, que se puede entrever un poco, como en las cuevas;

- En las de baúl o caja, se refieren a sitios con tapaderas, sin mirada humana ordinaria posible;

- En las de tela o telar, la dirigen hacía la capa visible que encubre lo que está debajo;

- En las de comal la dirigen hacía el conjunto, incluyendo la capa visible y el espesor casi invisible de la tapadera. 
Propiedades comunes de los diversos objetos escogidos como metáforas revelan la equivalencia del referente bajo la diferencia aparente de los vehículos. El mundo puede ser representado tanto por figuras cuadrangulares (casa, baúl, hilos de telar, etc.) como circulares. Los bordes del Tlalticpactli se dibujan como una cinta alrededor de un mantel o se comparan a orillas de comal, a cerros o a faldas de montañas.

\section{La Tierra como contenedor}

La cosmología mesoamericana ha dado lugar a una enorme cantidad de obras en disciplinas diversas. Los arqueólogos han identificado cosmogramas en la arquitectura. Las fuentes escritas necesitan un trabajo hermenéutico por etno-historiadores, como López Austin (1980, 1990, 1994), Graulich (1990), Broda y Báez Jorge (2001) y muchos otros. Nos apoyamos en algunos resultados que se admiten en la etapa actual. Los etnólogos han aportado datos frescos desde decenios y usaremos, a lo largo del artículo, unos estudios en pueblos del área oriental (figura 1), sin pretender a la exhaustividad.

Existen muchas imágenes del universo, contemporáneas o prehispánicas. Se notan variaciones de perspectiva: superior (forma cuadrangular, circular, flores de cuatro pétalos, ruedas, cruces, etc.) o lateral (pisos superpuestos, contenedores escalonados o no, animales, monstruos, siluetas de papel, etc.). Más allá de la variedad, consideramos que la Tierra se concibe como un contenedor con una superficie más o menos plana.

En el presente como en el pasado, la Tierra, Tlalli, se ve como una entidad en sí, enorme. Su nombre divino en los dialectos centrales es Tlaltecuhtli. Una división primordial distingue la cima y la parte baja de la Tierra. La corteza se nombra Tlalticpactli (locativo Tlalticpac). La parte de bajo - que los antropólogos llaman inframundo - es Tlali'tec, en el vientre de la tierra (interior), y Tlatzintlan, en la parte baja. En Chicontepec, dicen también Youalcalco, en la casa de la noche (Báez Jorge y Gómez Mártinez, 2000: 82). En la Sierra de Puebla, de dialecto náhuat, el inframundo se designa en su totalidad por Talocan (Tlalocan en dialecto central), pero este nombre es también él una subdivisión de su interior (Knab, 1991: 31).

Como punto de partida, construí dos patrones de analogías espaciales, que se relacionan con ideas de contenedores y de oscuridad (figura 10). El primer patrón sigue en 
tándem el camino del sol. De día, en el Tlalticpac, el sol aparece, anda arriba de este en oeste, aumenta de calor; de noche se mete en el Tlali'tec y se supone que lo recorre abajo de oeste en este. De la misma manera, la vida se desarrolla en la superficie terrestre iluminada, pero camina en el contenedor oscuro del inframundo. El segundo patrón se refiere a un camino entre el fondo del contenedor y su límite superficial, camino que puede continuar al exterior. Usando elementos relacionados con deidades nahuas del fondo, este paso puede compararse a un cordón umbilical, a la dirección ascendente del humo y del vapor, al escurrimiento y deslizamiento de gotas. En los dos patrones se encuentran analogías con procesos de preparación culinaria.

Existe un tercero esquema mesoamericano atestiguado: él de un recorrido en cruz de los supuestos caminos subterráneos, que empieza y se termina por el centro, en conexión con el cielo (Knab, 1991, 1995). Por falta de espacio, no lo comentaremos aquí, pues la analogía con la carrera supuesta del sol indica puntos de contacto significativos con la verticalidad (iconos del cordón, del humo y de las gotas).

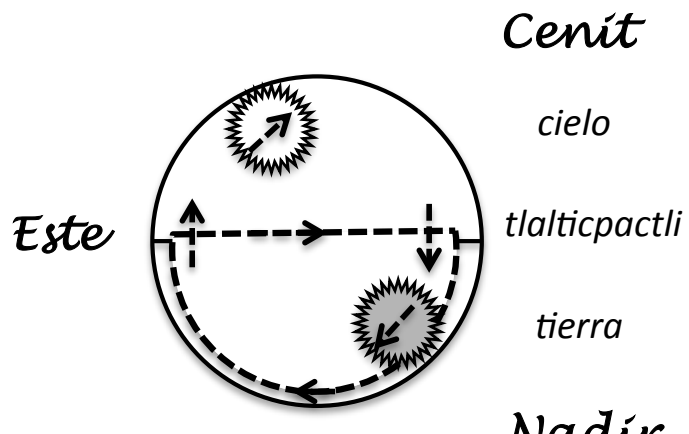

Patrón 1 Camino del sol

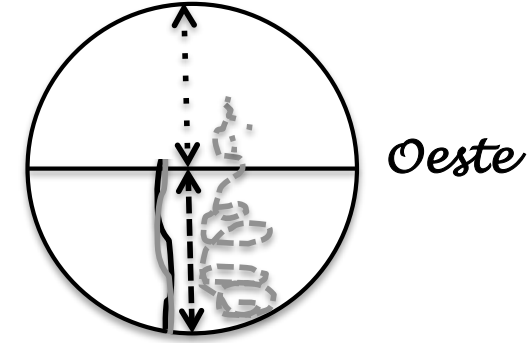

Patrón 2

Camino del humo y del cordón umbilical

(C) Marie-Noëlle Chamoux

Figura 10: Dos patrones de recorrido de la vida

\section{Tierra-cuerpo}

En la iconografía antigua como en encuestas contemporáneas, los Nahua consideran la Tierra como un ser vivo, que presenta analogías con un cuerpo animal intrínsecamente orientado, con carne (humus), con huesos (piedras), etc. (Stresser-Pean, 2005: 404; Báez 
Jorge y Gómez Martínez, 2000: 86), con entrada-boca al occidente, vientre-ombligo al centro y, a lo que parece, salida-cloaca al oriente. Su postura, paralela a la carrera del sol, se imagina horizontal como la de un animal, o a veces se presenta boca abajo. En toda la Mesoamérica antigua, se conocen representaciones por medio de animales, entre ellos cuadrúpedos como pecarí o anfibios como cocodrilos, tortugas. La piel rugosa, áspera o el caparazón desigual de éstos simulan la superficie terrestre con sus cerros, sus valles, sus selvas. Cipactli, cocodrilo, es un nombre del ser divino terrestre, entre los Nahua antiguos y contemporáneos.

La idea de un cuerpo animal se conecta lógicamente con un proceso biológico observable, incitando a una metáfora digestiva: el animal Tierra "traga" diariamente el Sol y lo expulsa, y pasa lo mismo a los hombres y otros vivos cuando mueren y cuando nacen. El proceso espacio-corporal y temporal de ingestión / digestión / excreción sirve de metáfora y se extiende al morir y al nacer. Con tales iconos en la mente, no sorprende que en Cuacuila, y en su área, un modo familiar de designar a los niños es cuitlame', excrementos, lo que recuerda que el nacimiento se hace por la parte baja del cuerpo (tzintli) y que se localiza en el tiempo. Los nińos nacen después del locutor adulto, lo siguen, son seres posteriores que aparecen por el trasero.

La oscuridad interna de un contenedor es una propiedad común al cuerpo animal o humano, a la Tierra y también a la semilla, pequeño contenedor oscuro que encierre un brote latente en su interior, y a recipientes hechos por el hombre.

\section{Tierra-artefacto contenedor}

Para imaginarse la forma de la Tierra, los Nahua recurren no sólo al modelo de un cuerpo animal, sino también a artefactos de los evocados. Abundan los esquemas en corte, unos remontando a épocas antiguas. Escogimos tres de los del oriente mexicano contemporáneo, que muestran la tierra y el cielo, de cada lado de una línea horizontal que señala la corteza terrestre Tlalticpactli con un punto occidental y otro oriental. De modo directo o no, evocan contenedores.

La figura 11 viene de la sierra norte de Puebla (dialecto náhuat, ver Beaucage, 2009) y representa la tierra con su interior como una escudilla. Da dos términos para la superficie 
terrestre: talmanik, taltikpak y el inframundo es talijtik, en el vientre de la tierra (y no "bajo la tierra").

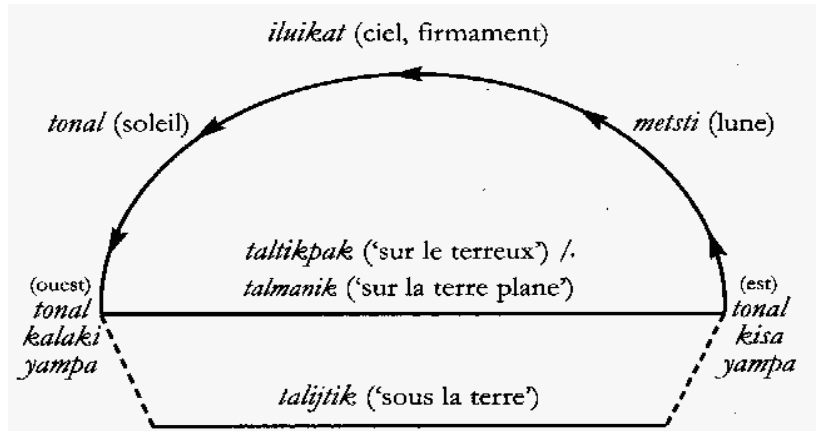

Figure 2.4. Le Cosmos (semanauak) selon les Natuas.

$\begin{array}{lll}\text { Dialecto náhuat } & \text { Dialecto central } & \text { Español } \\ \text { Iluikat } & \text { Iluicatl } & \text { Cielo } \\ \text { Taltikpak } & \text { Tlalticpac } & \text { Cima terrestre } \\ \text { Talmanik } & \text { Tlalmanic } & \text { Llanura terrestre } \\ \text { Talijtic } & \text { Tlali'tec } & \text { Vientro terrestre } \\ \text { Tonal } & \text { Tonalli } & \text { Sol } \\ \text { Metsti } & \text { Metztli } & \text { Luna } \\ \text { Tonal kalaki yampa } & \text { Tonal calaqui iampa } & \text { Lado de la puesta del sol } \\ \text { Tonal kisa yampa } & \text { Tonal quisa iampa } & \text { Lado de la salida del sol }\end{array}$

Figura 11: La tierra en forma de escudilla

(Sierra norte de Puebla, según Beaucage, 2009, traducciones de Chamoux)

La figura 12, la más completa, procede de la Huasteca (dialecto de la Huasteca, Chicontepec, ver Báez Jorge y Gómez Martínez, 2000: 84, 2001: 401) y presenta contenedores con escaleras. La comparación es explícita: la Tierra "es como el fondo de una olla que tiene trece escalones (...) el inframundo (...) se convierte en 'el fondo de una jícara’ (...)” (Báez Jorge y Gómez Martínez, 2000: 84-85). La forma escalonada es lógicamente compatible con los esquemas en pisos superpuestos que se conocen en otras 
fuentes y estudios. Además muestra explícitamente un camino de descenso al lugar de los muertos (Mictlan).

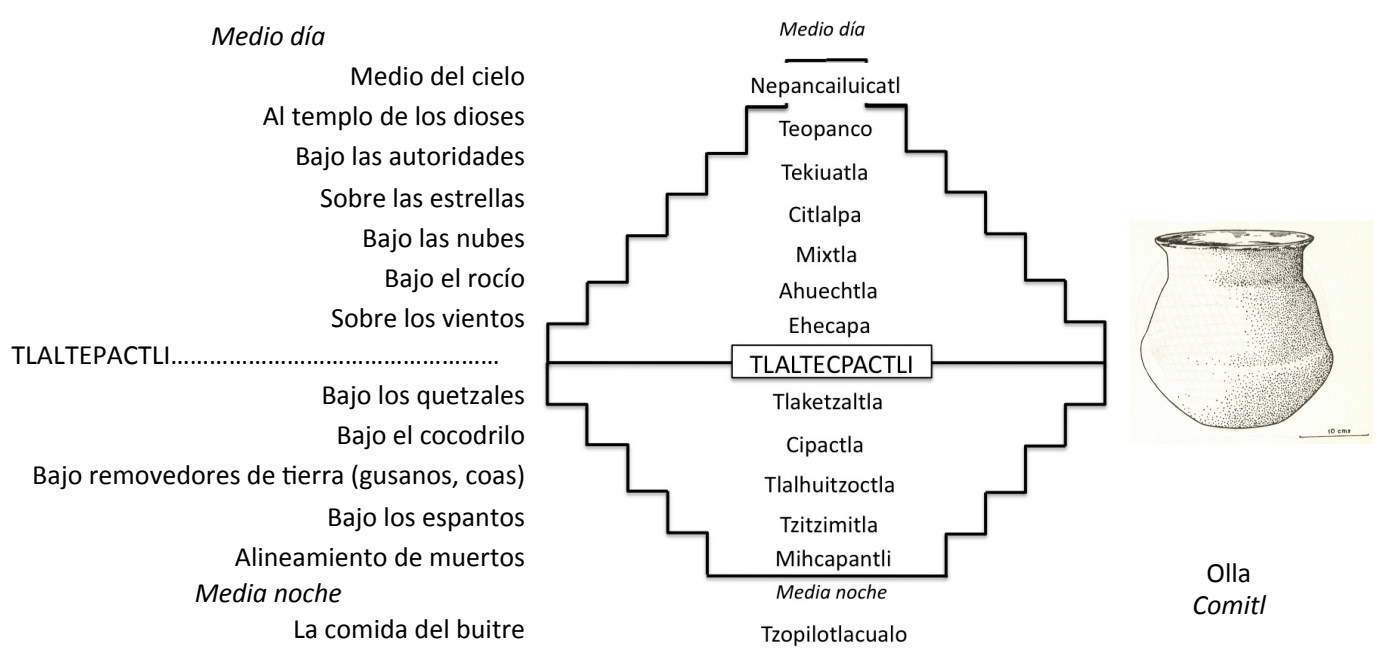

Figura 12: La tierra, contenedor escalonado (o con pisos)

(Chicontepec, según Báez Jorge y Gómez Mártinez, 2000, 2001, traducciones de M.-N. Chamoux)

(C) Marie-Noëlle Chamoux, según Báez Jorge y Gómez Martínez, 2000: 84

La figura 13 es nuestra - hecha a partir de datos de campo - y presenta un modelo provisional, con contenedores hemisféricos de tipo jícara y el glifo tzin horizontal como en un animal. Persisten dudas sobre la forma del océano, si se debe representar la Tierra flotando o bien descansando en el fondo, etc.
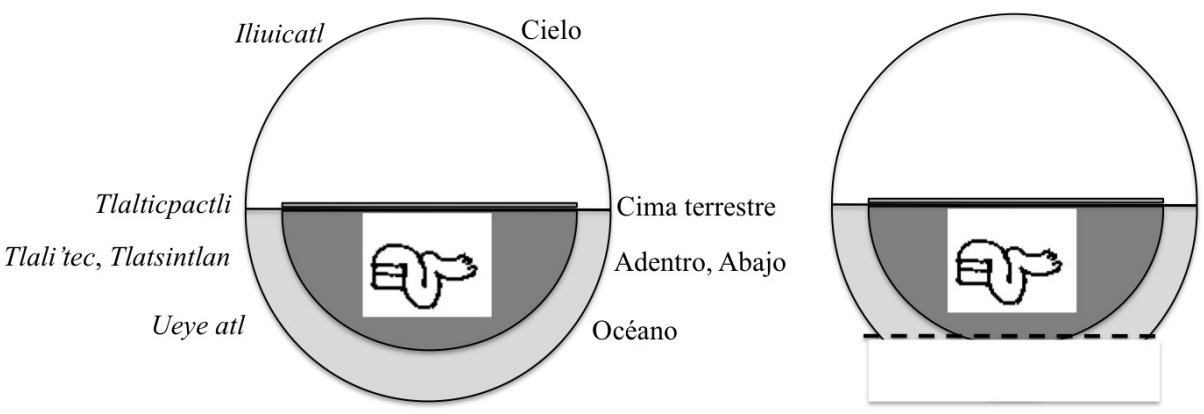

Figura 13: La tierra en forma de jícara

(norte de Puebla, según Chamoux) 
En los tres esquemas, la cara iluminada, que pisan los hombres, cubre los lugares oscuros. Arriba aparece el cielo Iluicatl (locativo iluicac) señalado por el camino del sol en la figura 11, y por contenedores boca abajo en las figuras 12 y 13. En efecto, ayer como hoy, los Nahua recurren a imágenes de contenedores para evocar el cielo: es una casa (Sahagún, 1950-1982, vol. 11: 247; Stresser-Péan, 2005: 398-39) ${ }^{10}$, o bien una jícara volteada (Cuacuila, datos de campo 1970). Notamos que, en las encuestas, el contenedor celeste no se asocia con la oscuridad, a pesar de que se vuelve oscuro cada noche. Los mesoamericanos explican que de noche el sol viaja en la Tierra, iluminando el mundo de "abajo". Los Nahua repiten que cuando es de día en el inframundo, es de noche aquí donde vivimos y vice-versa.

¿Cómo explicar que los dos contenedores, el terrestre y el celeste, pasan cada uno de la oscuridad a la claridad y la inversa, y que solamente el contenedor "Tierra" se asocia a una oscuridad esencial? La repuesta la encontramos en la deixis espacial implícita y su corolario epistémico. Encima, las cosas que quedan entre la planicie y la bóveda celeste se exponen a la vista de los hombres, con numerosos indicios, a la excepción de lo que se queda más allá del sol (Dios) que deslumbra y no se deja contemplar. La única parte visible del cuerpo terrestre es su cumbre. Desde ésta, queda poco visible el espesor de la corteza, capa fértil que permite solamente un acceso parcial a ella. En las profundidades inferiores, queda un espacio de tinieblas intensas, el "vientre" Tlali'tec o la parte trasera "nalgas, ano" Tlatzintlan. Resulta que el ser humano vivo puede ver el cielo empíreo, de día o de noche, pero nunca puede ver el cielo y el sol subterráneos. Para el ser humano, no hay simetría cognitiva entre la mitad superior y la inferior.

La división espacial entre la cumbre iluminada y lo que está debajo establece la condición humana. A cada espacio de la tierra corresponde un estado particular de los seres humanos, animales y plantas. Pasan del estado de vida en el Tlalticpactli a otras formas de existencia - muertos, semillas o brotes - en el Tlali'tec / Tlatzintlan. ¿Qué sucede a un existente en la superficie, y que le pasa cuando muere y entra en lugares de oscuridad subterráneos? 


\section{El curso de la vida (nemiliztli), análogo a la carrera del sol}

La estrategia de conocimiento náhuatl subdivide el contenedor Tierra en secciones que albergan dominios divinos invisibles organizados por analogía con pueblos, reinos o señoríos, con gobernantes principales y secundarios, con numerosos vasallos y mensajeros. Los distintos poderes tienen localizaciones definidas. Para comprender los procesos vitales, oscuros e invisibles, los seres humanos deben interpretar señales. Pero los indicios que se escapan de uno u otro sitio divino no son iguales ni en número ni en calidad informativa para los humanos "ordinarios", es decir para los que no son adivinos.

\section{Consolidación en el Tlalticpactli: consistencia, coagulación, endurecimiento}

El Tlalticpactli tiene su dios o señor, nombrado en Cuacuila Tlalticpac Tlacatl, que es "él que manda a la semilla”. Su dominio es la corteza terrestre, como la piel en la analogía animal o como la tapadera en la analogía técnica. Parece que tiene dos elementos con grados diferentes de "oscuridad": la planicie visible (Tlalmanic) y la capa fértil semi-visible (Tlalticpactli). En efecto, los hombres, en el curso de sus actividades productivas o rituales, tienen una posibilidad limitada de mirar en el espesor de la corteza (cuevas, hoyos) y de actuar en ella (ritos, agricultura). En la cima abundan indicios observables sobre la vida y lo vivo, señales que utilizan para representarse lo menos visible.

El crecimiento y el cultivo del maíz es el arquetipo que proporciona la metáfora mayor para representarse la vida de animados, retomando lo observado en plantas (López Austin, 1994). El proceso de crecimiento mismo tiene el valor de modelo general. Los vegetales nacen de semillas que se siembran en el suelo, lugar oscuro e interior ${ }^{11}$. Primero se ven duras, inertes, y después germinan, tornando a brotes tiernos, suculentos, aguados y frágiles... Los tallos se levantan, crecen (ixua), endurecen (uapaua), y terminan leñosos, rígidos, secos, duros. Los seres animados (yolque) conocen una secuencia análoga en su vida: se "siembran" (concepción) y después crecen (mozcaliya) y endurecen (uapaua) pasando de lo blando a lo duro, de lo acuoso a lo seco, de lo jugoso a lo leñoso. 
Un proceso culinario que se observa diariamente presenta una analogía con partes de este proceso vital. El comal, hemos dicho, es una metáfora corriente del Tlalticpactli, y sirve para tostar varios alimentos y sobre todo para cocer el pan de maíz (tortilla). Los Nahua presentan la tortilla como el arquetipo de la comida fuerte que nutre y da energía, y más que todo atestigua la calidad de ser humano verdadero de aquél que la come. Aún no hemos escuchado explícitamente la metáfora, pensamos que la secuencia de cocción puede aparentarse al proceso de la vida en el Tlalticpactli: hábilmente conformada por una mujer y depositada en el comal calentado, la tortilla se coagula, endurece, se vuelve consistente, se seca, su forma se estabiliza, y sale con forma regular, caliente, sabrosa y nutritiva. A lo largo del curso normal de su vida en la superficie, una especie de coagulación, efecto del calor del sol, estabiliza la forma y la consistencia del ser vivo.

A lo opuesto, la enfermedad realiza una dislocación de la persona, como dice la oración de un curandero interrogando a los dioses (Chamoux, 2012b):

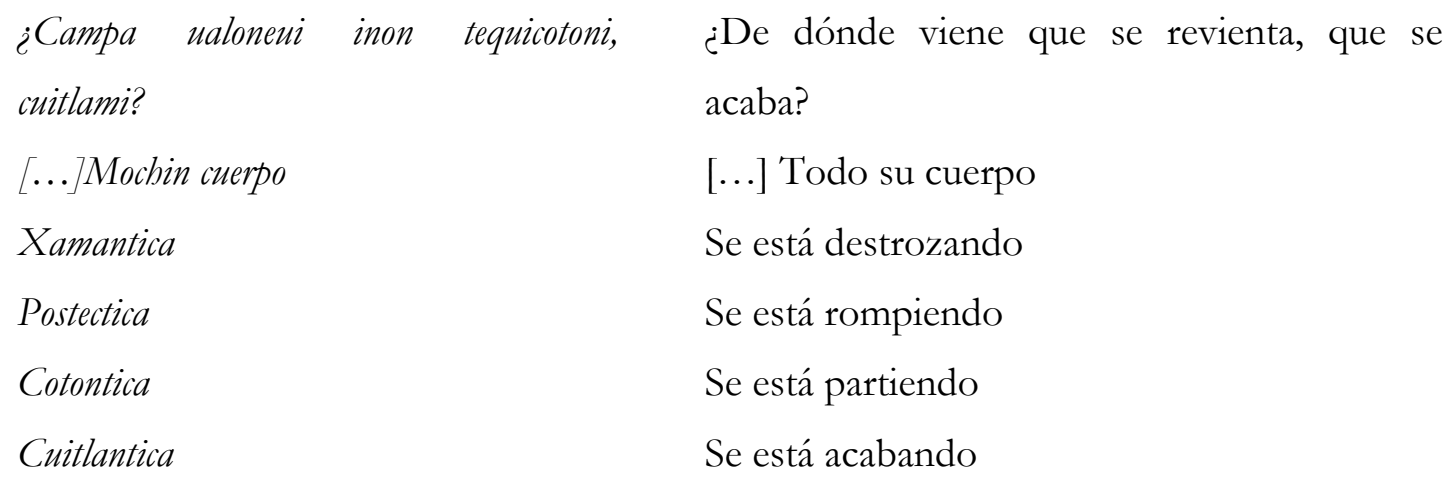

En Cuacuila, actos de curación de niños y enfermos consisten en apretarles fuertemente el cuerpo y los miembros con un rebozo. El método se conoce en la mayoría de los pueblos mesoamericanos. La meta es "componer" la persona para restablecer su consistencia.

\section{Oscuridad feroz en el Mictlan: descomposición, desecamiento}

Cuando muere, la persona opera un descenso, desde el Tlalticpactli, en el contenedor inferior del Tlali'tec / Tlatzintlan ¿Pero qué cosa hay ahí adentro-abajo y que sucede? Al lado occidental subterráneo, se imagina un itinerario que baja al reino feroz de Mictlan, 
el lugar generalista de los muertos (en la figura 12, el informante indica por donde él sitúa la bajada). Esta parte deja escapar en la superficie indicios y las observaciones humanas realizadas encima y permiten construir una idea relativamente precisa de lo que ocurre adentro-abajo. Tenemos muchas descripciones del Mictlan, tan antiguas como contemporáneas. Relatan una existencia cotidiana similar a la del Tlalticpactli, pero caracterizada por la disgregación, el pudrimiento, la ruina, la destrucción. Los muertos comen tortillas de ceniza, cosas apestosas, gusanos e insectos necrófagos, usan cosas rotas, etc. (para Cuacuila, ver Chamoux, 1980).

El hombre tiene conocimiento directo de las transformaciones que afectan a un cuerpo muerto. Continúa el proceso de desecamiento iniciado en la superficie, pues sale el jugo del cadáver (“espuma”, dicen los Nahua) y se pudre el cuerpo hasta la descarnadura y llega al estado de "huesos secos", como dicen. La hipótesis mesoamericana antigua plantea que entes divinos -los señores del Mictlan - devoran las partes blandas y las carnes. En el descenso al Mictlan, parece continuar el desecamiento empezado durante la vida en el Tlalticpactli, pero al contrario de mejorar la consistencia del cuerpo vivo, lo disloca y deshace sus formas. Lo recuerdan los ritos de entierro contemporáneos en el norte de Puebla, que requieren que se rompan y se tiren en la tumba los objetos personales del difunto, porque así los va usar en Mictlan.

Si consideramos las preparaciones de alimentos, los procesos en Mictlan para obtener huesos secos presentan analogías con ciertas técnicas humanas para deshacer las formas. Abajo, los dioses pelan los muertos como encima los humanos desgranan mazorcas almacenadas. Las deidades deshuesan los difuntos por medio de dientes (el dios de los muertos los "come") y de navajas (atributo del dios azteca de los muertos). Arriba, los hombres también deshuesan las carnes de maneras variadas (por dientes, navajas, cocción), y consideran los huesos como semillas de nuevos vivos. La analogía entre huesos y semillas es ampliamente atestada en toda el área mesoamericana: la evocaremos adelante en dos mitos, la leyenda de los soles en náhuatl (Códice Chimalpopoca, 1945) y el Popol Vuh en quiché (Christenson, 2007). 


\section{En el centro: destrucción y recreación de lo vivo}

Al final del descenso, en medio del contenedor, se encuentran los dominios divinos los más misteriosos. Es el punto donde se cruzan los dos patrones, el del curso subterráneo del sol, y el del camino entre la profundidad y el límite exterior.

Se topa aquí con el problema peliagudo del lugar divino que las antiguas fuentes nombran Tamoanchan, cuya traducción, localización y naturaleza se discuten y dan lugar a polémicas. En la actualidad, se tiende a establecer un consenso considerando que este lugar - o concepto - es el eje vertical del mundo, colocado en el centro y efectuando la síntesis de los rumbos y niveles del universo (López Austin, 1990, 1994 retomado por muchos autores).

¿Cómo este esquema vertical puede articularse con el patrón del camino del sol? Un examen anatómico ayuda a aclarar este punto. Un primer elemento es el ombligo stricto sensu, pequeńa zona con depresión o cicatriz en la barriga de un mamífero. En la analogía de la tierra como contenedor, corresponde al sitio el más bajo y profundo, al fin del descenso en un recorrido paralelo al curso del sol. Se sitúa en el eje del nadir. En Cuacuila, se dice que la tierra "tiene un hueco en el centro" (datos de campo, 2005). En la figura 12, esta zona se sitúa abajo y afuera del contenedor escalonado. Es un área localizada. En los contenedores oscuros de tipo jícara u olla, se alcanza al terminar la bajada, y se deja al empezar la subida al otro lado.

Un segundo elemento es el cordón umbilical, que es un camino y no sólo una zona. Evoca los recorridos verticales entre el fondo del contenedor y los niveles superiores (Figura 10). Hace eco a las interpretaciones de Tamoanchan como árbol cósmico central, cuya raíz se hunde en el centro del inframundo y cuya cima sube hasta la cumbre del cielo. López Austin dibuja su tronco en forma helicoidal, semejante a un cordón (1994: 225). Es una subida y bajada de dirección general vertical (un ascensor), y no oblicua y gradual como la carrera del sol (una escalera), si permiten tales metáforas.

Además de Tamoanchan, los dominios centrales llevan varios nombres. Los más relevantes para nuestro propósito evocan el ombligo, los huesos, la bajada y las preparaciones culinarias. Las fuentes citan Tlalxicco, lugar del ombligo de la Tierra, sitio "de la madre de los dioses, del padre de los dioses, lo que yace en el ombligo de la Tierra" ("in teteo innan, in teteo inta', in tlalxicco onoc" (Sahagún, 1950-1982, v. 6: 88). 
En Chicontepec, hoy, se menciona el estadio final de lo muerto: Tzopilotlacuallo, lo que comió el buitre (dejó solamente huesos): en la figura 12 lo colocan abajo y afuera del contenedor. Sahagún evoca la bajada, diciendo que "tamôhuanchân" significa "se baja a nuestra morada” (Sahagún, 1950-1982, v. 10: 190). Luis Reyes propone otra pista que conecta con procesos culinarios y no con un área localizadanos: "Tamohuan significa 'el dueño del maíz'. Tama o tomo es una raíz antigua que sólo aparece en las palabras como 'tamal' o maíz molido y cocido al vapor; 'nixtamal' o maíz cocido con cal o ceniza" (Amoxcalli, Transcripción paleográfica del manuscrito 210: nota 126).

En esta zona, la más profunda, descansan los huesos descarnados y secos de los muertos. En ciertas fuentes se dice que los guardan los señores del Mictlan (Códice Chimalpopoca, 1945). Otra fuente dice que los custodia la deidad masculina del fuego, el Viejo Dios ${ }^{12}$. En la Huasteca, nombran al dios central Xiuhtsin (grafía clásica repuesta), Venerada Lumbre (González González y Medellin Urquiaga, 2007) ${ }^{13}$. En los textos antiguos lo llamaban Huehueteotl (Ueueteotl), Viejo Dios, o Xiuhtecuhtli, señor de turquesa, es decir, de la lumbre (figura 9). Muchos autores piensan que es el mismo dios que Ometecuhtli, dios primordial, padre de los dioses y creador del mundo, junto con su mujer, Omesiuatl.

Ya que los dioses mesoamericanos van generalmente por pareja, lógicamente queda, cerca del viejo dios en el subterráneo, una deidad femenina que le corresponde. La encontramos como diosa del baño de vapor y de su hornito (tlexictli, "ombligo de fuego"), generalmente construido en el patio de la casa. En Cuacuila, nombran a la diosa Toueyesi'tsin, Nuestra Gran Abuela Venerada (mismo nombre que la Toci de los aztecas), o Temascaltenantsin, Venerada Anciana del baño de vapor.

Estas deidades del fuego parecen al origen mismo de la vida, manejando la transformación de lo muerto en lo vivo, juntando y procesando las substancias que provienen de los dominios colindantes, al oeste: los huesos; y, al este: el agua, como lo veremos. Sus reinos se localizan en lugares donde elementos en estado reseco (último paso de lo muerto) pueden servir de materia prima para crear nuevos seres en estado húmedo (que equivale a vivo). No se trata de resurrección individual ni de reencarnación personal, pero de la fabricación de un ser nuevo a partir de la materia prima de los muertos que son los vivos anteriores. El rol de estas deidades constituye el punto crucial del proceso de destruccióncreación de la vida. 
Toda la gente sabe, por observación, que el fuego provoca la destrucción suprema, la desecación completa y la cremación que reduce en cenizas, pero también fabrica lo mejor. Se supone que, en la oscuridad del Tlalitec / Tlatzintan, el dios del fuego termina de desecar todo lo muerto, mientras "encima", Tlalticpac, tuesta en el comal alimentos que mantienen la vida. Al final del descenso a través del Mictlan, él acaba de descarnar y de deshacer completamente las partes blandas de los cuerpos muertos.

En cuanto a la diosa abuela del temascal, una leyenda de Cuacuila dice que antes devoraba a los niños preparados en tamales, lo que es un detalle culinario icónico pues el tamal se cuece con vapor caliente. Ella convoca a elementos contrarios, el fuego y el agua, y provoca el efecto del primero sobre el segundo, produciendo agua caliente y vapor.

Arriba, en la casita para baño de vapor, produce un humo húmedo que, en la oscuridad, impregna a los cuerpos para sanarlos, calentarlos y limpiarlos de la suciedad. En la profundidad, lógicamente, interviene después del Viejo Dios del fuego destructor. Crea la vida a partir de lo destruido, y preside al parto que "hace aparecer" un nuevo ser en el Tlalticpactli. Su acción calienta y humidifica.

Señales de humidificación se encuentran claramente ilustrados en antiguas fuentes. En el Codex Vaticanus, que contiene un famoso esquema vertical del universo como apilamiento de pisos celeste, terrenal, e infernal, el piso inferior se llama Yzmictlan Apochcaloca, lugar de los muertos de obsidiana (comprender: re-secos), lugar ahumado de agua (comprender: vapor). Reiteramos que el icono en pisos es perfectamente compatible con la idea de contenedor, sea este cuadrangular o circular. La lámina 11 del Códice Borbónico representa la diosa Toci pariendo. Los colores de sus adornos, de tinta negra y roja (tlilli tlapalli), la colocan como diosa subterránea en contacto con lo muerto. A su lado se cruzan lo seco y lo húmedo representados enlazados como un ciempiés descarnado y un pequeño serpiente carnoso verde. Medialunas, en posición recta y no volteada, decoran los atuendos de la diosa, lo que no es tanto una marca de "deidad lunar" sino la señal de las ollas (comitl) llenas de agua, guardadas en la luna, que usa la diosa.

Aunque quede difícil precisar la localización respectiva de los dioses en el centro uno al lado del otro o apilados de abajo para arriba en el Tamoanchan vertical -, la secuencia temporal del proceso parece la siguiente. Primero, el viejo dios del fogón, quizá asimilable a Ometecuhtli, acaba de desecar y reduce en cenizas la forma corporal. Después de él, una diosa procesa los restos para preparar un nuevo cuerpo, impregnándolos de agua 
y de vapor como el maíz que se cuece en el interior de un recipiente, sea éste una olla o un temascal, que muchísimas veces se ha comparado a la matriz.

\section{Oscuridad feraz del Tlalocan: impregnación de líquido, ablandamiento}

Continuando a avanzar en el contenedor terrestre, se encuentra, al lado oriental subterráneo, el Tlalocan, gobernado por Tlaloc, "él que está junto a la Tierra”, y sus numerosos vasallos. Es el reino de la tierra feraz y de las reservas de semillas, de plantas, de animales y de aguas abundantes, que deidades reparten en la tierra desde los cerros y cuevas sagrados.

Los indicios observables de lo que sucede en el Tlalocan son escasos. Los habitantes de Cuacuila relatan señales que certifican su existencia: por cierta cueva emana un agua "que se parece a nixtamal" y se escapan animales: concluyen que "hay un pueblo debajo del cerro” y lo nombran Tlalucan (Cuacuila, datos de campo 1970-2010). Según los Nahua, la existencia cotidiana en el Tlalocan - donde van los muertos por causa del agua o de la centella -, es algo similar a la de la superficie, pero con abundancia permanente y dedicada al cuidado y a la multiplicación de especies, plantas y animales. Los moradores comen alimentos finos y lujosos, como atole de chocolate. Es el exacto opuesto de la existencia en el Mictlan.

Las referencias acuáticas abundan. Los textos antiguos hablan frecuentemente de los niños como preciosas gotas. En Cuacuila, comparan un abortón con una rana, animal anfibio, y alertan contra los peligros teratógenos para el feto, - entes devoradores asociados al agua: luna, arco-iris, deidades de los pozos, etc. (Cuacuila, datos de campo 1970-2010). Mitos, ritos y creencias establecen una analogía entre niños y cucurbitáceas tiernas, etc.

Pero queda misterioso para el hombre el desarrollo vital intrínseco. Los Nahua usan de analogías con vegetales: in selicayotl in itzmolincayotl, la germinación y el aumento (Sahagún, 1950-1982, v. 6: 36). En el texto contemporáneo ya citado se atestigua la metáfora de la germinación humana en la Tierra: sipa ye'uatl inin tech seliya, [la Tierra] una vez nos hizo germinar (Romualdo Hernández, 2000: 56). Señalamos que el verbo que traducimos para germinar es el radical de selic que se usa para decir "blando", "suave", 
"tierno", hablando de una planta o de una fruta y designa la luna en fase creciente. Lo que es joven es tierno, repleto y agranda. Parece que germinar es inflar y ablandar.

En otros textos, los hombres son flores, espiguillas. Oraciones a las deidades del trueno, escuchadas en Cuacuila en 1970, recuerdan a los dioses la nostalgia de los hombres, porque antes de nacer eran como brotes protegidos en lugares de oscuridad. Pero ahora se encuentran llorando sobre el suelo terrestre (locativo tlalpan, y no tlalticpac): “(...) sus hijos, sus niños, sus niños en el suelo, sus flores en el suelo, sus mariposas en el suelo, sus espiguillas en el suelo, sus espejos en el suelo, sus brotes en el suelo (...)” (Chamoux, 2012b: 83).

Después del nacimiento, se prolonga la analogía entre cosas acuosas y niños, visible en un sinnúmero de metáforas, de creencias y de ritos antiguos y contemporáneos. En el tiempo de los aztecas, sacrificaban nińos cuando faltaba la lluvia. Hoy sacrifican pollitos para pedir el agua a los dioses, pero niños siempre han tenido un papel central en la ceremonia. En Cuacuila, antaño mandaban niños y niñas para traer agua de cuevas sagradas y rociar la iglesia y las imágenes de la Virgen para que viniera la lluvia benéfica (Cuacuila, notas de campo, 1970).

El proceso vital completo no empieza con la concepción y el nacimiento. Incluye a la muerte. Implica agentes divinos que cumplen con varias funciones para producir la vida. Si es relativamente fácil para el ser humano observar los pasos de la vida en la superficie y los de la bajada destructiva en Mictlan, quedan poco inteligibles las maneras de formar nuevos seres "en la oscuridad", por las escasas posibilidades de observaciones humanas. Es donde intervienen más analogías con acciones técnicas humanas.

\section{Algunas acciones técnicas para crear la vida}

Retornamos a la zona del ombligo, en el fondo del contenedor terrestre. De aquí parte el movimiento vertical, el camino de las deidades del fuego hacía arriba. Los dioses - como otros dioses mesoamericanos - se hacen múltiples y desembocan en el Tlalticpactli en una infinidad de sitios.

En toda la Mesoamericana, se venera un dios del fogón de la cocina (tlecuilli). En la Huasteca, el dios central se llama Xiuhtsin (grafía clásica repuesta), Venerada Lumbre 
(González González y Medellín Urquiaga, 2007). En el norte de Puebla, el dios aflora en cada casa, desde la profundidad, y preside a la fundación de cada unidad matrimonial y residencial. Recibe culto en la ceremonia de casamiento. Se le pide permiso para que suelte la novia que va con su esposo a un nuevo hogar, con un nuevo fogón (Cuacuila, Naupan, datos de campo 1970 a 2010).

Lo mismo ocurre con la diosa del bańo de vapor, casita construida en el patio de la casa. Desde la profundidad, aflora en el hornito (tlexictli, "ombligo de fuego") del temascalli. La abuela divina del baño de vapor todavía preside a los ritos de parto, de limpia y de curación y recibe ofrendas.

Estas deidades tienen funciones ambiguas: moran en la oscuridad la más profunda, pero sus ascuas suben para iluminar y calentar la superficie. Radican al fondo del inframundo pero se manifiestan arriba en el Tlalticpactli en cada casa (Lupo, 2001: 343344); se ven debajo del comal, en el horno en forma de cuevita del temascalli, en el incensario presente en cada hogar.

Sus acciones se realizan tanto en el fondo como en la superficie. El dios del fuego deseca y destruye "abajo"; pero "encima" tuesta en el comal alimentos que mantienen la vida. Acaba de descarnar los muertos "abajo"; pero "encima" cuece la carne del guisado para separarla del hueso y hacerla comestible. Quema y destruye el incienso copal, pero produce su humo seco y oloroso que alimenta a los dioses, etc. La misma ambigüedad se ve en el caso de la diosa del temascalli, que puede devorar a niños en tamales, pero cura, limpia, repone energía a la gente con el vapor caliente.

¿Cómo actúan estas deidades en los procesos vitales? Los documentos antiguos y encuestas evocan muchas acciones técnicas de entes divinos en los mitos de creación del mundo. El Popol Vuh califica la pareja de viejos dioses creadores de toltecas, palabra azteca designando los artesanos que lograban la perfección en su arte. El texto enumera varios oficios: joyeros (las joyas son los hombres), escultores de piedras, de madera, haciendo efigies de hombres, etc. (Christenson, 2007: 20). En una época (cerca de 1970) en que no llegaban en los pueblos nahuas las narraciones del pasado indígena vistas por la escuela o por académicos, los habitantes del norte de Puebla mencionaban en su mito de la creación el tallo de huesos para hacer efigies humanas: 
[Dios dice al Demonio Yéyecatl :] "Buscamos donde están los huesos, donde se perdieron esos hijos míos. Entonces ahí conoceremos cuáles son los huesos de mujer, y cuáles son los huesos de hombre”. Bueno. Entonces ahí empezaron a llegar. Dice [Dios]: "Este es hueso de hombre, mira, y este es hueso de mujer". Entonces dice el Demonio: "Ahora sepas y escuchas. Vamos a cortar figuras [xi'xima: 'pelar como fruta', traduce el narrador, es decir, sacar el hueso], vamos hacer humanos los huesitos, un muńeco, y también los huesos de mujer, y entonces juntos los acostaremos, y entonces a los siete días vendremos llegando" (Cuacuila, datos de campo, 1970).

Las fuentes evocan métodos culinarios para transformar lo muerto en lo vivo. Cuando el dios Quetzalcoatl, después de robarse los huesos de hombres, llegó a Tamoanchan (aquí puede designar la zona baja del ombligo terrestre), la diosa, Quilachtli Cihuacóhuatl, molió los huesos (verbo tesi, que designa la preparación de masa de maíz) y después los bañó (del verbo tema, que da temascalli, baño de vapor) en un precioso lebrillo "para exprimir agua" (chalchiuhapazco). A continuación, Quetzalcoatl los mojó con la sangre que por sacrificio sacó de su miembro viril, ejemplo seguido por varios dioses (Códice Chimalpopoca, 1945). En la leyenda de Cuacuila, Dios "bendice" a los muñecos de hueso, probablemente echándole agua bendita, para que no se los apropie el Demonio. En el Popol Vuh, la abuela divina Xmucane también recrea el hombre y la mujer a partir de granos de maíz que muele y moja (B'elejeb' k'u u ka'l Xub'an Xmuqane. Echa'xokik, Ruk'ja' rope'nal, Nine therefore its grindings She did. Food entered, With water its strength (Christenson, 2007: 171).

En la oscuridad terrestre se realiza la destrucción completa de lo que todavía quedaba de la forma humana viva, es decir, los huesos. La materia prima molida se vuelve sin forma, hasta que, por humidificación, torna a masa blanda que es posible conformar.

¿Qué semejanzas hay o no hay entre los procesamientos culinarios divinos y los de los humanos? Existen elementos de recetas en el Chimalpopoca y el Popul Vuh, aun conllevan probablemente un implícito importante. En las dos fuentes, la diosa muele primero los huesos o el maíz, y después los moja. En los dos casos, se sugiere que después las diosas exprimen el agua. El orden de las acciones no concuerda con el procedimiento el más común y cotidiano, que comienza por fabricar nixtamal, es decir, hervir el maíz duro con cal o ceniza antes de molerlo para hacer masa ${ }^{14}$.

En el norte de Puebla, una receta implica de moler el maiz sin hervirlo antes, de lavarlo y hacerlo agriar en agua, para hacer un atole muy espeso. Se conoce en otros 
pueblos como atole agrío, el cual en Cuacuila se llama pichi y se prepara para las fiestas agrarias del mes de mayo (Cuacuila, datos de campo, 1969-1970).

Comparamos las secuencias operativas evocadas en los mitos antiguos y las prácticas cotidianas corrientes:

- Grupo de etapas 1. Desgranar equivale a deshuesar. "Encima", el proceso empieza por desgranar mazorcas secas, como muertas, escogidas entre las que fueron almacenadas en el granero de la casa en la época de Todosantos (mibcatonalli, tiempo de los muertos). Es deshacer su forma, y vemos una analogía clara con la disgregación del cuerpo en Mictlan. Vemos también que los huesos, como las mazorcas, pueden quedarse almacenados y no reciclados necesariamente de inmediato. Encima, se obtiene granos de maíz muy duros y secos, como abajo lo son los huesos de muertos al final de su procesamiento subterráneo. Para la creación del hombre, la deidad parte de huesos en las "leyendas de los soles" de los antiguos Nahua y en cuentos de Cuacuila de 1970, y parte de granos de maíz en el Popol Vuh. Considerar las propiedades duro y seco reduce la variación entre el quiché y el náhuatl a una misma representación que se refiere a un mismo proceso, con equivalencia de huesos y granos.

- Grupo de etapas 2. Existen dos posibilidades de preparación, con o sin nixtamal (maíz pre-cocido con ceniza o cal). Para el nixtamal, la cocinera pone a hervir agua con cal o ceniza en una olla (comit) y cuando hierve echa adentro los granos. Después se asegura que los granos de maíz estén ablandados, listos para moler, porque pierden su película. Los mitos citados no señalan las etapas del nixtamal.

- Grupo de etapas 3. Hay una variante, con o sin nixtamal. Primero, con nixtamal, la secuencia es lavar - escurrir - moler para obtener masa. Segundo, sin nixtamal, la secuencia es moler - lavar - escurrir: se muelen los granos duros, y después de molidos se remojan en agua fría y se exprime la masa antes de preparar el alimento. Este segundo método es él más parecido al que usa la diosa: echa en el agua los huesos (Códice Chimalpopoca) o los granos (Popol Vuh) ya molidos, los lava enseguida, los prensa y escurre. En los dos casos, la forma inicial de los huesos o la del maíz ha desaparecido se ha vuelto indeterminada.

- Grupo de etapas 4. Conformar el alimento. Del más líquido al más consistente, los alimentos son: Primero, atole. Para el atole agrio, se deja el maíz molido y mojado para que fermente. Segundo, tamales. A partir de nixtamal molido, 
los forman y los envuelven en hojas unos por unos. Tercero, tortilla. A partir de nixtamal molido, se da forma a las tortillas (tlaxcalli), haciendo discos los más perfectos posibles.

- Grupo de etapas 5. Cocer. Las etapas de cocción no aparecen en los dos mitos citados. Primero, atole. Se cuece en una olla la masa diluida en agua, removiendo con una cuchara, hasta que se espese; entonces se agrega sabores y olores (dulce, frijol cocido, etc.). Segundo, tamales. Se ponen todos juntos en una olla grande, con un poco de agua y helechos al fondo, se tapa bien la olla con hojas, plástico u otro, y se pone a hervir. Tercero, tortilla. Se extiende la tortilla en el comal calentado metáfora del Tlalticpactli. Al depositar las tortillas en el comal, la cocinera las observa una por una, las despega del comal y las voltea para una cocedura homogénea y las saca antes que se queman.

La fabricación de atole agrio es la técnica que más se asemeja a lo que hacen las diosas en los dos mitos.

Con el atole, aparece una nueva analogía. Su aspecto evoca el semen, que en náhuatl se dice omisetl (omicetl), el cual significa "escarcha de hueso". Para los Nahua, es una substancia que proviene de los huesos, precisamente de la médula (López Austin, 1980: 190). Atribuyen la gravidez a la coagulación del semen en la mujer: de ahí viene un nuevo ser. Fabricando atole, la diosa fabrica el semen al origen de la vida.

Las recetas evocadas tienen un efecto común, el de aumentar la consistencia de los alimentos, aun en grados diferentes: semilíquido es el atole, blando es el tamal, compacta es la tortilla. De la misma manera, difiere el fraccionamiento del producto consumible: papilla indistinta, tamal formado y envuelto separadamente pero cocido en grupo, tortilla formada y cocida individualmente. Podemos imaginar que la serie de consistencias y grados de individuación de los alimentos de maíz proporciona un icono de la formación del cuerpo y del desarrollo de la persona. La vida naciente escondida pasa por varias consistencias y formas preparadas por varios agentes divinos en la "oscuridad". Abajo, dislocan lo vivo hasta hacerlo polvo, ceniza, moltura. En el fondo de la olla terrestre remojan lo molido, dándole progresivamente consistencia y forma. Arriba en el Tlalticpactli, la forma se estabiliza y la consistencia endurece. El proceso termina de nuevo con la destrucción, el consumo. 
En la producción de la vida, los Nahua plantean la necesidad de agentes divinos que realizan procesos técnicos por analogía a los que los seres humanos realizan en la superficie terrestre. A cada deidad su cargo técnico: los señores del Mictlan descarnan, devorando lo blando; el viejo dios del fuego deseca los huesos y los reduce en ceniza; la vieja diosa del temascal, y las diosas de su grupo, muelen y remojan esta materia y la cuecen en recipientes; el Tlaloc y sus vasallos impregnan de agua la "semilla" vegetal o humana, transforman lo duro en blando llenándolo de agua y hacen inflar la vida, de manera que la "semilla" vegetal o humana germine y crezca. Al final de todas estas acciones, un nuevo ser está listo para nacer en la superficie, andar y vivir (verbo nemi). La creación de la vida resulta de la acción conjunta de poderes divinos en el interior oscuro de la Tierra, así como en el vientre del animal y de la semilla.

La pareja divina del fuego - y particularmente la diosa - es la que reúne la cooperación de los otros poderes divinos más especializados y procesa la mezcla inicial de la cual surge la vida. Se piensa evidentemente en el concepto de Tamoanchan como eje central del mundo que sintetiza los elementos de los diversos reinos del mundo.

El patrón de la carrera solar linear que expuse ayuda a representar el curso de la vida, nemiliztli. Pero en cuanto a la creación de lo vivo, en el sentido de yoliztli, vida intrínseca, indica solamente el sitio de su momento inicial en los lugares oscuros donde se guardan ciertas materias primas. La formación de lo vivo se aclara por otras metáforas, como las culinarias evocadas, que se refieren a procesos de mezcla de ingredientes y acciones divinas.

En todos los esquemas mesoamericanos que se conocen, se destaca una orientación epistemológica. Se da preeminencia a la interrogación sobre los procesos, más que sobre las substancias, buscando salir de lo obscuro y de lo confuso por medio de modelos de recorridos y secuencias de cambios. Los Nahua han tratado de identificar y nombrar discontinuidades, sin dejar de reconocer humildemente sus ignorancias: una metodología en la cual un hombre de ciencia moderna se reconoce perfectamente. 


\section{Notas}

${ }^{1}$ Un esbozo de este texto fue presentado al taller "Des êtres vivants et des artefacts. L'imbrication des processus vitaux et des processus techniques", organizado por Ludovic Coupaye (University College London), Perig Pitrou (CNRS, Laboratoire d'anthropologie sociale), Laura Rival (Oxford), Paris, 13 de noviembre de 2013.

${ }^{2}$ Usamos la terminología pragmática y constructivista, que emplea definiciones más precisas que la de cultura.

${ }^{3}$ Llamamos náhuatl clásico el idioma hablado en el área de México-Tenochtitlan o Anahuac, en el siglo XVI. El náhuatl, bien conocido, se habla todavía en varias partes de la República Mexicana con inflexiones dialectales regionales. No tiene normas ortográficas unificadas y usamos, salvo excepción, un sistema clásico simplificado, a veces aplicándolo a la grafía original de la fuente.

${ }^{4}$ El tema iconográfico de lo oscuro y nebuloso es bien conocido de los arqueólogos. Ver por ejemplo Hernández Sánchez (2004), sobre vasijas que vienen de Puebla-Tlaxcala, Oaxaca y Veracruz decoradas con dibujos de oscuridad y humo "similares a la manera en que éste se pinta en los códices (p. ej., Borbonicus 1991, p. 5; Cospi 1994, p. 12; Vaticanus B 1993, p. 31; Vindobonensis 1992, p. 6)".

5 Varía la terminología en castellano. La palabra "chaman" - discutible - es de muy reciente importación. Los Nahua del oriente mexicano hablan de adivinos o curanderos.

${ }^{6}$ En el quiché del Popol Vuh, y en el mismo contexto discursivo que él que examinamos aquí, se usa también "aparecer", opuesto a un verbo que podría significar "esconder" o bien "sembrar". Dice el traductor: "The manuscript reads enaxibal (that which is hidden). This is likely a scribal error for anaxibal (that which is sown). Throughout the text, sowing and dawning are paired as referents to the creation". (Christenson, 2007). Quizá no es un "error", sino se trata de un juego de palabra, ya que el acto de sembrar es él de esconder una semilla en lugar oscuro: la tierra.

7 Wimmer (s.f.) comenta "Les montagnes qui seraient en réalité des vases ou des réservoirs (comitl, calli), pleins d'eau (ca tenticah in ât)" (Sahagún, 1950-1982, v. 11: 247), y lo confirman numerosas pinturas y esculturas antiguas.

8 Desde la izquierda: según Matricula de Huexotzingo; los tres siguientes: según Matricula de tributos, Codex Mendoza; los dos últimos: según Codex Xolotl.

9 "In tlaltikpakttli ye'uatl nochipa tletektsintli, ye'uatl nochipa yitos, te'uan a'mo tlen tikpiya, santipanouauni iixko ome, yeye xinitl, iixco timotikipanoua, sipa ye'uatl inin tech seliya, tioui, tiasi ikamak in tlaltikpaktli." (Romualdo Hernández, 2000: 56).

10 Wimmer (s.f) comenta: “(...) le ciel (ilhuicath) serait comme une maison (calli) avec des murs d'eau (acaltecbtli)" (Sahagún 11: 247). ). Stresser-Péan habla de "mundo", pero se trata del cielo (2005: 398-399).

${ }^{11}$ En Cuacuila, la analogía se encuentra en los ritos de siembra, pues mientras la Tierra recibe la semilla vegetal seca y dura en el suelo, los trabajadores reciben un tamal con un huevo duro, semilla animal coagulada y endurecida (Cuacuila, datos de campo, 1970).

12 Nota Johansson: "En la versión del Códice florentino, Quetzalcóatl irá a Tlillan, Tlapallan, y conversará con un anciano: 'Ce tlacatl ompa tlapia, ye buebuetlacatl. A(n)mononot- qazque (Un hombre allá aguarda, es viejo. Conversarán)'. Este viejo es Huehuetéotl, el dios anciano, señor del fuego 
Xiuhtecuhtli” (Johansson, 2012: 75).

13 El radical xiuh- designa la turquesa, las hojas vegetales, el ciclo del año, pero, en incorporación, toda la gente de habla náhuatl lo comprende inmediatamente como lumbre o fuego.

14 No hablaremos aquí de las preparaciones de maíz tierno (elote) que se tuesta o se transforma en atole.

\section{Referências bibliográficas}

Amoxcalli, diccionario de glifos en línea, México, Ciesas, http://amoxcalli.org.mx/diccionario.php

\section{ANÓNIMO}

(sin fecha) Dictionnaire espagnol-nahuatl Bnf $n^{\circ}$ 362, Paris, Bibliothèque nationale de France, manuscrito. Paléographie: S. de Pury Toumi. En línea: http://celia.cnrs.fr

BÁEz Jorge, Felix y Gómez Martínez, Arturo

2000 "Los equilibrios del cielo y de la tierra: Cosmovisión de los nahuas de Chicontepec”. Desacatos 5: 79-94.

2001 “Tlacatecolotl, Señor del bien y del mal (la dualidad en la cosmovisión de los nahuas de Chicontepec”. In BrodA, Johanna y BAEZ-JORGE, Arturo, Cosmovisión, ritual e identidad de los pueblos indígenas de México, México, Fondo de cultura económica, pp. 391- 451.

BEAUCAgE, Pierre

2009 Corps, cosmos et environnement chez les Nahuas de la Sierra Norte de Puebla, Une aventure en anthropologie. Montréal, Lux Éditeur. 
BRAUDEL, Fernand

1959 "Histoire des Civilisations: le Passé explique le présent". In L'Encyclopédie française, tome XX: Le Monde en devenir (histoire, évolution, prospective), Paris, Société nouvelle de l'Encyclopédie française.

BRODA, Johanna y BÁEZ JORGE, Felix (orgs.)

2001 Cosmovisión, ritual e identidad de los pueblos indígenas de México. México, Consejo Nacional para la Cultura y las Artes, Fondo de Cultura Económica.

\section{Chamoux, Marie-Noëlle}

1980 “Orphée nahua”. Amérindia, 5: 113-122.

2012a "Persona, animacidad, fuerza". In Pitrou, Perig; Valdés, María del Carmen Valverde; y NeURATH, Johannes (orgs.), La noción de vida en Mesoamérica, México, Universidad Nacional Autónoma de México, Instituto de Investigaciones Filológicas / Centro de Estudios Mexicanos y Centroamericanos, pp. $155-180$.

2012b "Él habla nublado. Un discurso ritual en náhuatl del siglo XX (norte de Puebla)". In Martel, Patricia y Gubler, Ruth (orgs.), Enlaces con lo divino en la ritualidad indígena, Editorial Académica Española, pp. 69-88.

Christenson, Allen J.

2007 Popol Vuh: literal translation. Electronic version of original 2004 publication, Mesoweb Publications, 1-304. http://www.mesoweb.com/publications/Christenson/ index.html

\section{Codex Borbonicus}

Bibliothèque de l'Assemblée Nationale, Paris, Foundation for the Advancement of Mesoamerican Studies, inc. Akademische Druck - u. Verlagsanstalt - Graz. En línea http://www.famsi.org/research/graz/borbonicus/thumbs_0.html 


\section{Códice Chimalpopoca}

1945 (traducción Primo Feliciano Velázquez), México. En línea: http://americaindigena.com/s17doc6.htm

Codex Vaticanus 3738

1979 Graz; en línea:

http://www.famsi.org/research/loubat/Vaticanus\%203738/thumbs0.html

GonZÁlez GonZÁlez, Mauricio y Medeldin Urquiaga, Sofía

2007 "Pueblos indígenas de México y agua: nahuas de la Huasteca". In: Atlas de culturas del agua en América Latina y el Caribe, Instituto Nacional de Antropología e Historia / Centro de Investigación y Capacitación Rural A.C., en línea.

GraULiCH, M.

1990 Mitos y rituales del México antiguo. Madrid, Colegio Universitario de Ediciones Istmo.

HABERMAS, Jürgen

1987 Teoría de la acción comunicativa. Madrid, Editorial Taurus.

HERNÁNDEZ SÁNCHEZ, Gilda

2004 “Temas rituales en la cerámica 'tipo códice’ del estilo mixteca-puebla”. Journal de la société des Américanistes, 90(2): 7-34.

JOHANSSON, Patrick K.

2012 "La muerte en la cosmovisión náhuatl prehispánica: consideraciones heurísticas y epistemológicas”. Estudios de cultura náhuatl, 43: 47-93.

KNAB, Tim J.

1991 "Geografía del inframundo". Estudios de cultura nábuatl, 21: 31-57. 
1995 A War of Witches: A Journey into the Underworld of the Contemporary Aztecs. Nova York, Harper Collins.

KIRCHHOFF, Paul

1943 "Mesoamérica: sus límites geográficos, composición étnica y caracteres culturales". Acta Americana, 1(1): 92-107.

\section{LAUNEY, Michel}

1980 Introduction à la langue et à la littérature aztèque, t. II: Littérature. Paris, L'Harmattan.

1988 "Le linguiste et le funambule: Réflexions sur la spécificité et l'universalité linguistiques et culturelles". Amérindia, 13: 169-192.

LÓPEZ AusTin, Alfredo

1980 Cuerpo humano e ideologia: las concepciones de los antiguos nahuas. México, UNAM, Instituto de Investigaciones Antropológicas.

1990 Los mitos del tlacuache: caminos de la mitología mesoamericana. México, Alianza Editorial Mexicana.

1994 Tamoanchan y Tlalocan. México, Fondo de Cultura Económica.

LuPO, Alessandro

2001 "La cosmovisión de los nahuas de la Sierra de Puebla”. In BRODA, Johanna y BÁEZ-JORGE, Félix (orgs.), Cosmovisión, ritual e identidad de los pueblos indígenas de México, México, FCE, CNCA, pp. 335-389.

Perez Tellez, Ivan

2002 “La cosmovisión nahua de Cuacuila: una aproximación etnográfica”. México, tesis para licenciatura en etnología, ENAH, INAH, SEP. 
Romualdo Hernandez, Josué 2000 Nauatla’toli: lengua Náhuatl, Norte de Puebla, Tercer grado. México, Secretaria de Educación Pública.

SAHAGÚn, Fray Bernardino de 1950-1982 Florentine Codex: General History of the Things of New Spain, 13 vol., Santa Fe (translated by Ch. E. Dibble \& A. J.O. Anderson).

STRESSER-PEAN, Guy

2005 Le Soleil-Dieu et le Christ: La Christianisation des Indiens du Mexique. Paris, L'Harmattan.

2009 Teotihuacan, Cité des Dieux, Catalogue de l'exposition. Paris, Somogy, éditions d'Art et Musée du quai Branly.

WENGER, Etienne

1998 Communities of Practice: Learning, Meaning, and Identity. Cambridge, Cambridge University Press.

WimMer, Alexis

(sin fecha) (comp.) Dictionnaire de la langue nahuatl classique. En línea: http://www.sup-infor.com/navigation.htm 


\title{
The Places of Darkness: Nahuatl Epistemology of Life and Everyday Techniques
}

\begin{abstract}
Among the ancient and contemporary Nahuatl there is a strong epistemic concern about the possibility to understand how the Universe works, and the invisibility and the unintelligibility of processes of life and death. They say the processes occur in "places of the night", in the darkness. These places are located into the seeds and into the bodies of animate beings, including the Earth, seen as a giant animal. Everyday artefacts are used as metaphors for these places and what facts they reveal or not about life: house, bowl, water bottle, pot, trunk, loom, clay griddle etc. The Nahua use the model of the path of the Sun to locate places of darkness and they compare life with texture of growing plants. The paper describes the routes, the deities of Earth and their functions, and technologies used as metaphors of divine actions for creating life. It particularly details analogies with cooking methods for processing corn.
\end{abstract}

KEYWORDS: Nahuatl, death, life, underworld, Earth, gods, everyday artifacts, cooking 